\title{
ESTER PLASTICIZERS BASED ON FATTY ACIDS FROM SOYBEAN OIL USED IN PELICULOGEN COMPOSITIONS
}

\author{
SORINA BORAN, SABINA NITU ${ }^{\mathrm{a}^{*}}$
}

\begin{abstract}
In this paper is described the synthesis and characterization of esters based on soybean oil fatty acids and an assessment of their potential use as plasticizers in wood, concrete or metal paints. Esters of fatty acids were obtained in a chemical reactor with microwave heating, using soybean oil fatty acids and $n$-butanol or isopentanol in acidic conditions.
\end{abstract}

Keywords: ester, vegetable oil, fatty acids esters, microwave reactor, peliculogen

\section{INTRODUCTION}

Synthetic ester oils and vegetable oils are base oils in the production of adhesives with superior properties [1-5].

Processes for the synthesis of ester compounds in microwave heating reactors lead to the production of advanced purity products. Also, the use of this process has the advantage of shortening the reaction time, ultimately resulting in high reaction conversions [6-8].

Energy efficient processes and environmental friendly ones designed to replace the classical technologies are the aim of modern technologies. Reactions performed in bubble column reactors in polymerization [9-12] or in esterification processes may be considered to be environmentally protective ones and with a low energetic consumption [13]. As presented by Popa et al. [14-17] polymers synthesized in a bubble gas column reactor are ecological ones, because they do not contain residual monomer. An important technological issue is the intensification of heat transfer of all thermal processes, so the calculation of boiling heat transfer coefficients may be of high value [18-21].

a Politehnica University Timișoara, Faculty of Industrial Chemistry and Environmental Engineering, Bv.V. Pârvan 6, 300223, Timișoara, România

Corresponding author: sabina.nitu@upt.ro 
An important issue in present researches represents the negative effects of industrial activities on the environment. Some of the solutions described in literature are reducing wastes by recycling some of these materials [22-25], reusing wastes to obtain other useful products [26-27] or immobilizing other hazardous waste [28-29] and replacing of raw materials with new products.

\section{RESULTS AND DISCUSSION}

Physico-chemical properties of two types of ester products prepared by the esterification of soy bean fatty acids with $n$-butanol (P1) and respectively isopentanol (P2), are shown in Table 1.

Table 1. Physico-chemical properties of the synthesized esters P1 și P2

\begin{tabular}{|l|c|c|}
\hline \multicolumn{1}{|c|}{ Property } & $\mathrm{P} 1$ & $\mathrm{P} 2$ \\
\hline Density, $\rho^{20}\left[\mathrm{~kg} \mathrm{~m}^{-3}\right]$ & 880.5 & 1100.5 \\
\hline Refractive index, $\mathrm{n}_{\mathrm{D}} \mathrm{zU}$ & 1.4545 & 1.4600 \\
\hline Viscosity, $\mathrm{n}^{20}[\mathrm{mPa} \mathrm{s}]$ & 81.33 & 82.66 \\
\hline Saponification index, $\left[\mathrm{mg} \mathrm{KOH} \mathrm{g}^{-1}\right]$ & 222 & 150 \\
\hline Acid number, $\left[\mathrm{mg} \mathrm{KOH} \mathrm{g}^{-1}\right]$ & $<1$ & $<1$ \\
\hline lodine index, $\left[\mathrm{g} \mathrm{I}_{2} 100 \mathrm{~g}^{-1}\right]$ & 110 & 111 \\
\hline
\end{tabular}

Both products $\mathrm{P} 1$ and $\mathrm{P} 2$ have density, refractive index and viscosity values comparable to those of vegetable oils. In all cases, the acidity index is subunit. lodine index values for the synthesized compounds are comparable to those of lower unsaturated oils.

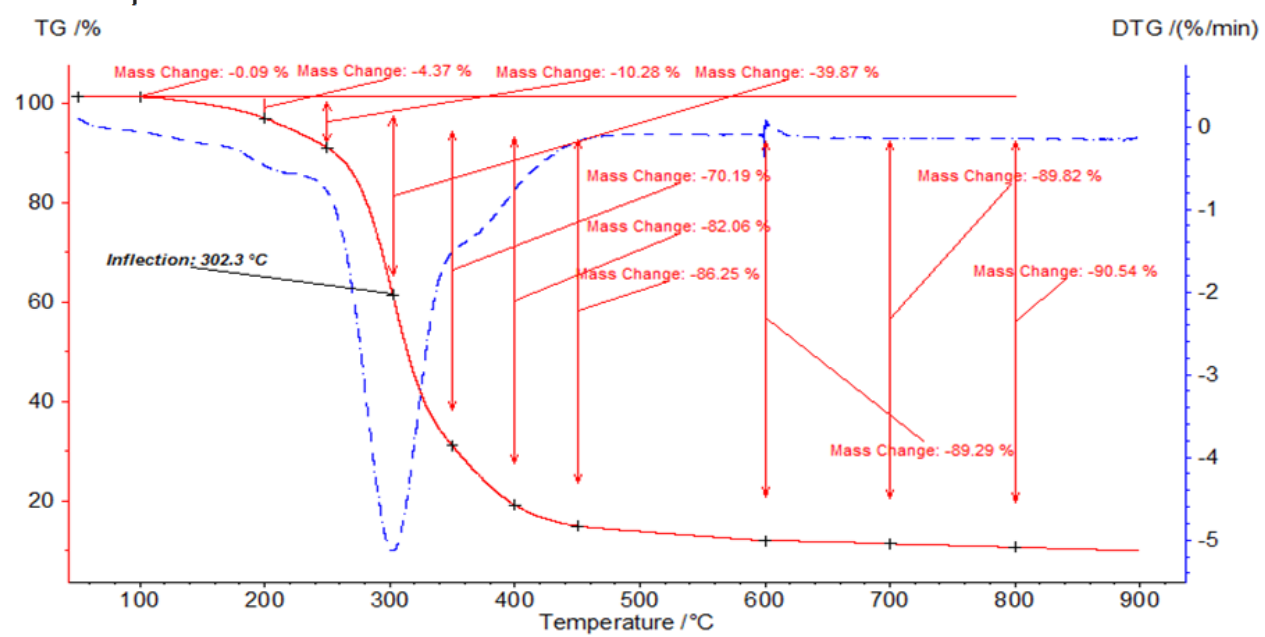

Figure 1. TG/DTG curves - P1 sample in nitrogen atmosphere

Figures 1 and 2 present the TG/DTG curves for the synthetized compounds $\mathrm{P} 1$ and $\mathrm{P} 2$ in nitrogen atmosphere. 
It can be observed a good thermal behavior, where the weight loss is insignificant, up to about $200^{\circ} \mathrm{C}$. Above $250^{\circ} \mathrm{C}$, the mass loss rises as the temperature is higher. In both cases, both for compound P1 and for compound P2, total mass loss occurs above $500^{\circ} \mathrm{C}$.

In the case of $\mathrm{P} 1$ sample (figure 1) the TG curve shows a continuous mass loss process with a major loss at $302.3^{\circ} \mathrm{C}$, loss of $39.87 \%$ and a maximum of $90.54 \%$ at $800^{\circ} \mathrm{C}$.

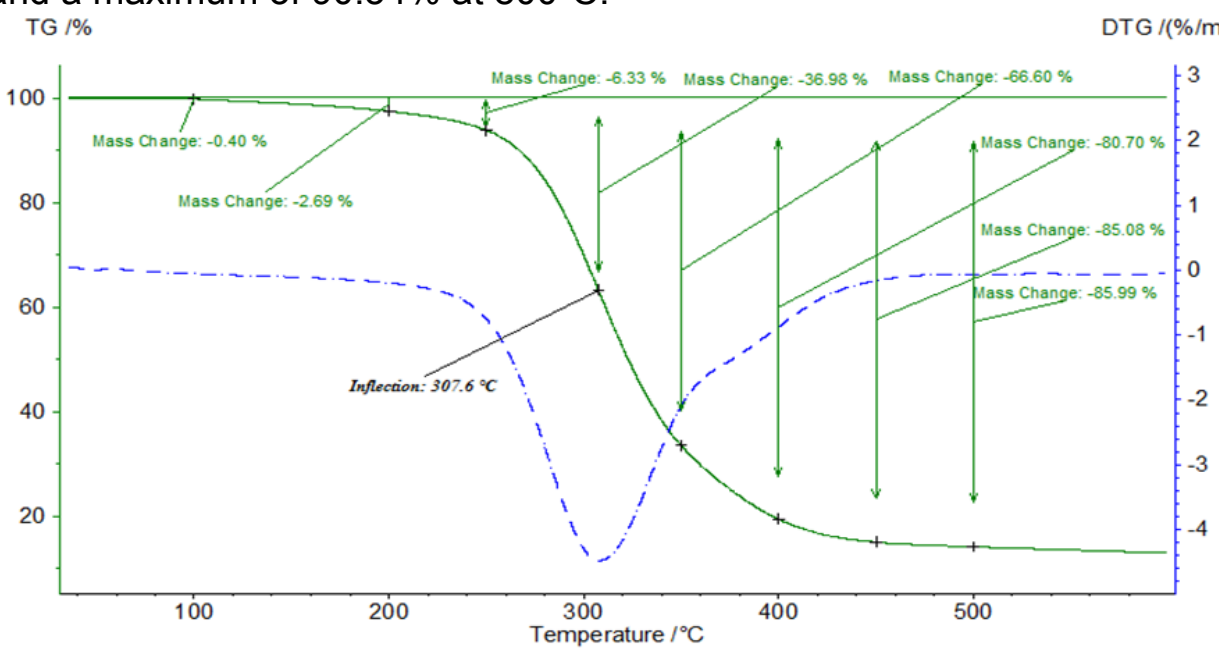

Figure2. TG/DTG curves - P2 sample in nitrogen atmosphere

Table 2. Characteristics for coatings type composites based on nitrocellulose based films obtained with the synthesized ester products P1, P2

\begin{tabular}{|c|c|c|c|}
\hline \multirow[t]{2}{*}{ Technical characteristics } & \multicolumn{3}{|c|}{ Sample } \\
\hline & 1 & 2 & 3 \\
\hline \multicolumn{4}{|c|}{ For the liquid product } \\
\hline Aspect & VOF & VOF & VOF \\
\hline Content in nonvolatile subst., $2 \mathrm{~h}, 120^{\circ} \mathrm{C}, \%$ & 38 & 42 & 42 \\
\hline Leakage time, cup DIN $4 \mathrm{~mm}, 20^{\circ} \mathrm{C}$, sec. & 50 & 52 & 53 \\
\hline Density, $20^{\circ} \mathrm{C}, \mathrm{gr} / \mathrm{cc}$ & 1050 & 1051 & 1052 \\
\hline Fine friction, microns & 15 & 15 & 15 \\
\hline \multicolumn{4}{|l|}{ Film } \\
\hline Aspect & $\mathrm{HF}$ & $\mathrm{HF}$ & $\mathrm{HF}$ \\
\hline Drying time, $\mathrm{D}$ type, at $20^{\circ} \mathrm{C}, \mathrm{h}$ & 0.5 & 1 & 1 \\
\hline Erichsen elasticity, $\mathrm{mm}$ & 7.2 & 7.6 & 7.8 \\
\hline Adherence, grid $2 \mathrm{~mm}$, grip figure & 2 & 2 & 2 \\
\hline Flexibility, mm & 3 & 3 & 3 \\
\hline Thickness of the dry film, $\mu \mathrm{m}$ & 20 & 20 & 20 \\
\hline Resistance to hit-directly, $0.5 \mathrm{kgf} / \mathrm{cm}^{2}$ & 25 & 30 & 35 \\
\hline Persozhardness, sec & 153 & 131 & 130 \\
\hline Degree of gloss angle $60^{\circ}, \%$ & 70 & 75 & 71 \\
\hline
\end{tabular}

VOF- Viscous HomogeneFluid, HF -Homogene Film 
Analogue to sample P1, the sample P2 (figure 2) on the TG curve also shows a continuous mass loss process with a major loss at $307.6^{\circ} \mathrm{C}$, of $36.98 \%$ and a maximum of $85.99 \%$ at $500^{\circ} \mathrm{C}$.

After characterization from the physico-chemical point of view of an organic substance, the synthesized esters were analyzed as plasticizers in nitrocellulose-based films and chlorinated rubber lacquer-based films compositions.

Table 2 presents the analytical values for coatings type composites based on nitrocellulose-based films obtained with the synthesized products.

The samples evaluated were based on nitrocellulose films, introducing the P1 and P2 synthesized products as follows:

- sample 1: contains only primary plasticizer (di-2-ethylhexyl phthalate) $(1.87 \%)$, with no content of P1 or P2;

- sample 2: besides the primary plasticizer, contains $6.25 \% \mathrm{P} 1$;

- sample 3: besides the primary plasticizer, contains $6.25 \% \mathrm{P} 2$,

- $\quad$ P1 and P2 have the role of secondary plasticizers.

Nitrocellulose based films have the following composition: nitrocellulose (17\%), resin CSM45 (13\%), titanium (20\%), di-2-ethylhexyl phthalate $(1.87 \%)$, nitro diluent (48.13).

\section{Interpretation of results:}

For the liquid product: the appearance of the samples is of a viscous homogeneous fluids; the content of non-volatile substances is slightly increased at samples 2 and 3 , respectively, against the control sample (sample 1); the leakage time is only slightly modified in the samples where the synthesized products were added, ranging from the standard range: $45-80 \mathrm{~s}$; The density of samples with the addition of plasticizers (secondary) - P1 and P2 - does not change essentially; Addition of samples P1 and P2 does not affect friction.

For the film: appearance - homogeneous; the drying time by the introduction of any of the two synthesized plasticizers increases; the Erichsen elasticity increases at the introduction of $\mathrm{P} 1$ and $\mathrm{P} 2$ products, which, in its turn, brings an improvement over the standard sample (1); the adhesion, flexibility and thickness of the film does not change when adding the synthesized products; impact resistance is improved most in sample 3 , with efficacy as plasticizers P2 > P1; in samples 2 and 3, their hardness is lower than the standard sample (1), which means that the two synthesized products act as secondary plasticizers; the degree of gloss increases by adding the two synthesized compounds.

Table 3 presents the analytical values for composites based on chlorinated rubber lacquer based films compositions obtained with the synthesized products. 
ESTER PLASTICIZERS BASED ON FATTY ACIDS FROM SOYBEAN OIL ...

Table3. Characteristics for composites based on chlorinated rubber lacquer based films compositions obtained with the synthesized products

\begin{tabular}{|c|c|c|c|}
\hline \multirow{2}{*}{ Technical characteristics } & \multicolumn{3}{|c|}{ Sample } \\
\hline & 4 & 5 & 6 \\
\hline \multicolumn{4}{|l|}{ Liquid } \\
\hline Aspect & VOF & VOF & VOF \\
\hline Content in nonvolatile subst., $2 \mathrm{~h}, 120^{\circ} \mathrm{C}$, [\%] & 45 & 49 & 49 \\
\hline Leakage time, cup DIN $4 \mathrm{~mm}, 20^{\circ} \mathrm{C}$, [s]. & 80 & 70 & 65 \\
\hline Density, $20^{\circ} \mathrm{C},\left[\mathrm{g} / \mathrm{cm}^{3}\right]$ & 1106 & 1107 & 1108 \\
\hline Fine friction, [microns] & 15 & 15 & 15 \\
\hline \multicolumn{4}{|l|}{ 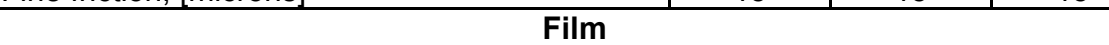 } \\
\hline Aspect & $\mathrm{HF}$ & $\mathrm{HF}$ & $\mathrm{HF}$ \\
\hline Drying time, $\mathrm{D}$ type, at $20^{\circ} \mathrm{C},[\mathrm{h}]$ & 1 & 2 & 2 \\
\hline Erichsen elasticity, $[\mathrm{mm}]$ & 4.2 & 7.8 & 7.8 \\
\hline Adherence, grid $2 \mathrm{~mm}$, grip figure & 2 & 2 & 2 \\
\hline Flexibility, [mm] & 5 & 3 & 3 \\
\hline Thickness of the dry film, $[\mu \mathrm{m}]$ & 25 & 25 & 20 \\
\hline Resistance to hit-directly, $0.5 \mathrm{kgf} / \mathrm{cm}^{2}$ & 10 & 35 & 35 \\
\hline Persozhardness, [s] & 66 & 60 & 62 \\
\hline Degree of gloss angle $60^{\circ},[\%]$ & 70 & 81 & 84 \\
\hline
\end{tabular}

VOF - Viscous Homogene Fluid, HF - Homogene Film

The samples evaluated were based on nitrocellulose film, introducing the P1 and P2 synthesized products as follows:

- sample 4: represents the standard sample with no content of P1 or P2;

- sample 5: contains $6.25 \% \mathrm{P} 1$;

- sample 6: contains $6.25 \% \mathrm{P} 2$.

- $\quad \mathrm{P} 1$ and P2 have the role of secondary plasticizers.

Chlorinated rubber lacquer-based films have the following composition: chlorinated rubber (35\%), chlorinated paraffin $(5 \%)$, diluent $(60 \%)$.

\section{Interpretation of results:}

For the liquid product: No large changes are seen in the liquid product, except that leakage time decreases with the addition of compound $\mathrm{P} 1$, and by the addition of compound P2 it decreases more than in sample 4, and even 5; the rest of the technical characteristics remaining approximately constant.

For the film: the Erichsen elasticity is greatly improved when adding the two synthesized compounds (from 4.2 to $7.8 \mathrm{~mm}$ ). Another characteristic that shows us the effectiveness of P1 and P2 as plasticizers is the resistance to impact which is much higher for samples 5 and 6 (35 cm).

Decreasing of hardness value (from $66 \mathrm{~s}$ for the standard to $60-62 \mathrm{~s}$ for the analyzed samples) as well as increasing the degree of gloss (81\% with $\mathrm{P} 1$ and $84 \%$ with $\mathrm{P} 2$ respectively) proves the role of plasticizers of P1 and $\mathrm{P} 2$ products. 


\section{CONCLUSIONS}

In the present paper, the main topics are the synthesis and characterization of esters based on soybean oil fatty acids and the assessment for their use as plasticizers in composites of nitrocellulose based films and chlorinated rubber lacquer based films compositions. Esters of fatty acids were obtained in a chemical reactor with microwave heating, using as an acidic component soybean oil fatty acids, and $n$-butanol and isopentanol as the hydroxyl component. The reactions occurred in the presence of the catalyst, $p$ toluenesulfonic acid ( $0.3 \%$ versus fatty acids in soybean oil), at reflux temperature.

The introduction of P1 and P2 compounds into nitrocellulose-based films compositions results in the improvement of the following features: Erichsen elasticity, impact resistance and gloss degree. The adhesion, flexibility and thickness of the film does not change when adding synthesized products. The drying time increases, and these mixtures can be used if a slower drying is desired. In terms of hardness, the synthesized compounds act as secondary plasticizers.

The introduction of $\mathrm{P} 1$ and $\mathrm{P} 2$ compounds into composites based on chlorinated lacquer based films compositions leads to an improvement in the following characteristics: Erichsen elasticity and impact resistance. No large changes are seen in the liquid product, except that leakage time decreases with the addition of compounds P1 and P2. The other technical characteristics remain approximately constant. Decreasing the value of hardness and increasing the degree of gloss again prove the role of plasticizers (especially secondary) of P1 and P2 products.

\section{EXPERIMENTAL SECTION}

Esters of fatty acids were obtained in a microwave reactor. The acidic component composed of the soybean oil fatty acids, combined with two different alcohols: $n$-butanol which gave esters mixture P1, and respectively isopentanol (3-methyl-1-butanol) which yielded esters mixture $\mathrm{P} 2$. The reactions were carried out in the presence of the catalyst, the $p$ toluenesulfonic acid, at the reflux temperature.

Synthetic variants thereof are shown in Table 4.

The physico-chemical properties of fatty acids from soybean oil: appearance: viscous liquid without mechanical impurities; color: yellow; molecular weight, $\mathrm{g} /$ mole: 280 ; density at $20^{\circ} \mathrm{C}, \mathrm{g} / \mathrm{cm}^{3}: 0.89$; melting point, ${ }^{\circ} \mathrm{C}$ : $14-16$; acid number, $\mathrm{mg} \mathrm{KOH} / \mathrm{g}: 193.4$; refraction index, la $20^{\circ} \mathrm{C}: 1.458$. The alcohols used are from Fluka. The characteristics of the chemical 
reactor with microwave heating are: model: MW-2000; microwave power: :0 $\sim 1800 \mathrm{~W}$; microwave frequency: $2450+50 \mathrm{MHz}$.

Table 4. The synthesis variants of esters from soybean oil fatty acids

\begin{tabular}{|l|c|c|c|}
\hline \multirow{2}{*}{ Raw materials } & \multirow{2}{*}{ MU } & \multicolumn{2}{c|}{ Synthesis variant abbreviations } \\
\cline { 3 - 4 } & & $\mathrm{P} 1$ & $\mathrm{P} 2$ \\
\hline soybean oil fatty acids & mols & 1 & 1 \\
\hline n-butanol & mols & 1.3 & - \\
\hline isopentanol & mols & - & 1.15 \\
\hline$p$-toluenesulphonic acid & $\%$ & 0.3 & 0.3 \\
\hline \multicolumn{4}{|c|}{ Reaction conditions } \\
\hline Time of reaction & min. & 240 & 280 \\
\hline Temperature of reaction & ${ }^{\circ} \mathrm{C}$ & $118-160$ & $118-180$ \\
\hline
\end{tabular}

The variation of the acid number of the reaction mass according to the reaction time was the tracking reaction parameter.

For esters mixture P1, synthesis parameters are drawn in Table 5.

Table 5. Reaction parameters for the esters $\mathrm{P} 1$

\begin{tabular}{|c|c|c|}
\hline Time, $\min$ & Temperature, ${ }^{\circ} \mathrm{C}$ & Acid number $[\mathrm{mg} \mathrm{KOH} / \mathrm{g}]$ \\
\hline 0 & 13.3 & 148.8 \\
\hline 15 & 108.8 & 48.86 \\
\hline 30 & 116 & 17.93 \\
\hline 60 & 117.8 & 10.27 \\
\hline 90 & 117 & 10.1 \\
\hline 120 & 120.4 & 9.54 \\
\hline 180 & 127.5 & 7.92 \\
\hline 240 & 139.9 & 6.48 \\
\hline
\end{tabular}

For P2, synthesis parameters are presented in Table 6.

Table 6. Reaction parameters for the ester $\mathrm{P} 2$

\begin{tabular}{|c|c|c|}
\hline Time, $\min$ & Temperature, ${ }^{\circ} \mathrm{C}$ & Acid number, $\mathrm{mg} \mathrm{KOH} / \mathrm{g}$ \\
\hline 0 & 14 & 147.54 \\
\hline 30 & 103 & 72.65 \\
\hline 60 & 107 & 58.76 \\
\hline 90 & 117 & 38.85 \\
\hline 120 & 118 & 26.96 \\
\hline 150 & 129 & 20.04 \\
\hline 180 & 140 & 16.34 \\
\hline 225 & 140 & 8.62 \\
\hline 280 & 176 & 3.34 \\
\hline
\end{tabular}

Conversion of the reaction in both cases is shown in Figures 3 and 4. 


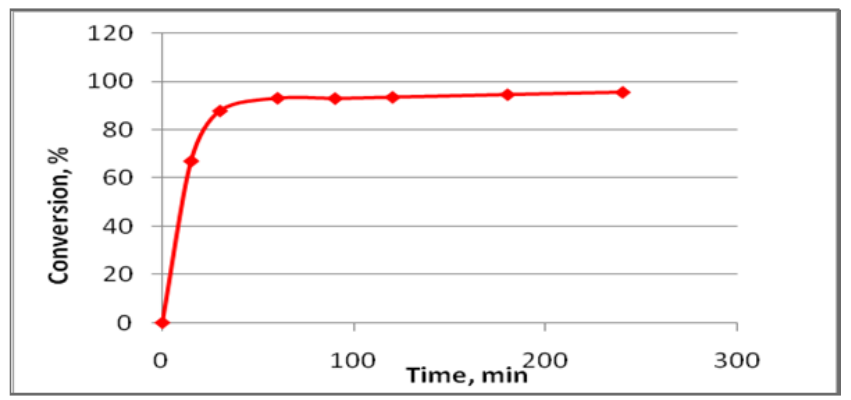

Figure 3. Conversion variation - P1 synthesis

From the chart depicted in Figure 3, there is a sharp increase in conversion in the first 30 minutes followed by a slow increase, so in the end a very good conversion of about $95.63 \%$ is obtained.

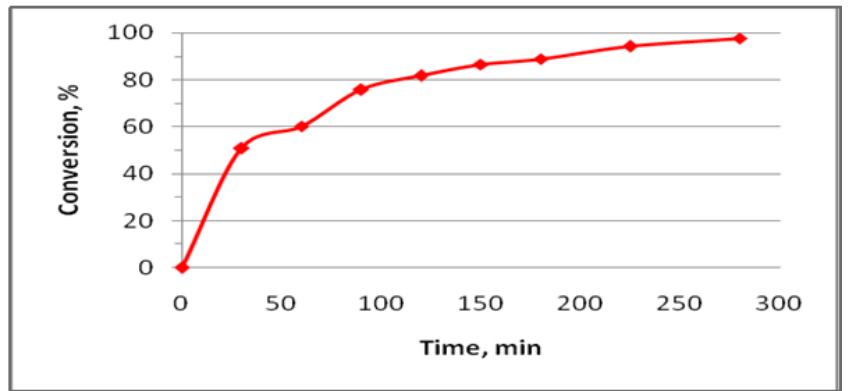

Figure 4. Conversion variation - P2 synthesis

In the case of synthesis $\mathrm{P} 2$, the variation of the conversion achieved by reaction time (Figure 4) is gradual and almost constant over time, reaching a $97.74 \%$ conversion.

\section{Methods:}

a) Structural characterization of $\mathrm{P} 1$ and $\mathrm{P} 2$ esters synthesized: the dynamic viscosity - the viscometer type RV-Rheotest (EBV PrüfgeräteWerkMedingen / Dresden); refractive index - Abbe refractometer at $20^{\circ} \mathrm{C}$; density - the pycnometer at $20^{\circ} \mathrm{C}$; the acid number - according to SR ISO 3682; saponification index - ISO 3657: 2013 iodine index - according to SR EN ISO 3961: 2013A; thermogravimetric analysis (TG)/(DTG) and differential scanning calorimetry (DSC) were performed with $\mathrm{NETZSCH}$ STA apparatus STA449F1A 449F1-0220-M. A quantity of between $3 \div 7$ 
mg sample was heated in a crucible of $\mathrm{Al} 2 \mathrm{O} 3$, with the rate of $5^{\circ} \mathrm{C} / \mathrm{min}$., under a nitrogen atmosphere in the temperature range of $25 \div 900^{\circ} \mathrm{C}$.

b) Evaluation of P1 and P2 synthesized esters as plasticizer for protective coatings: aspect - visual; the dynamic viscosity - the viscometer type RV-Rheotest (EBV Prüfgeräte-WerkMedingen / Dresden); content in nonvolatile subst. - SR EN ISO 3251:2008; drying time -SR EN ISO 91176:2012; Erichsen elasticity -SR EN ISO 1520:2007; adherence -SR ISO 2409:2013; flexibility -SR EN ISO 1519:1999; thickness of the dry film - SR ISO 2808:2007; resistance to hit-directly - SR EN ISO 6272-1:2012; Persozhardness - SR EN ISO 1522:2007; degree of gloss angle - SR EN ISO 2813:2003.

\section{REFERENCES}

1. M. Suzuki, Y. Taira, C. Kato, K. Shinkai, Y. Katoh, Journal of Dentistry, 2016, doi: 10.1016/j.jdent.2015.11.005.

2. J. Li, J. Luo, X. Li, Z. Yi, Q. Gao, J. Li, Industrial Crops and Products, 2015, 74, 613.

3. E. Lépine, B. Riedl, X.-M. Wang, A. Pizzi, L. Delmotte, J.-M. Hardy, M. J. R. Da Cruz, InternationalJournalofAdhesion\&Adhesives, 2015, 63, 74.

4. S. Boran, S. Nitu, Revista de MaterialePlastice, 2017, 54, 2, 386.

5. W. Maassen, M.A.R. Meier, N. Willenbacher, International Journal of Adhesion \& Adhesives, 2016, 64, 65.

6. P.N. Dange, V.K. Rathod, Resource-Efficient Technologies, 2017, 3, 1, 64.

7. T. Lieu, S. Yusup, M. Moniruzzaman, Bioresource Technology, 2016, 211, 248.

8. S.P. Bowen, D.R. Kanis, C. McDaniel, R.C Richter, Journal of Chemistry and Biochemistry, 2014, 2, 2, 1.

9. N.Plesu, G., Ilia, G. Bandur, S.Popa, Journal of the Serbian Chemical Society, 2005, 70, 10, 1169.

10. N. Plesu, G., Ilia, S. Iliescu, A. Popa, G. Bandur, S.Popa, MaterialePlastice, 2004, 41, 3, 143.

11. N. Plesu, G. Bandur, I. Manoviciu, S.Popa, D.Jurcau, MaterialePlastice, 2003, 40, 1, 21.

12. N. Plesu, R. Rad, I. Manoviciu, G. Bandur, S.Popa, Revista de Chimie, 2003, 54, 8, 685.

13. S. Popa, S.Boran, Materialeplastice, 2016, 53, 3, 410.

14. S.Popa, C.Csunderlik, V.Jascanu, D.Jurcau, N.Plesu, Materialeplastice, 2004, 41, $2,62$.

15. S. Popa, C.Csunderlik, V. Jascanu, D. Jurcau, N. Plesu, Materialeplastice, 2003, 40, 4, 177.

16. S. Popa, V. Jascanu, D. Jurcau, N. Plesu, Revista de chimie, 2003, 54, 7, 595. 
17. S. Popa, C.Csunderlik, S. Florea, V. Jascanu, N. Plesu,Revista de Chimie, 2002, 53, 4, 259.

18. D. Kohn, S. Popa, Experimental Heat Transfer, 1999, 12, 3, 193.

19. S. Popa, S.Boran, Thermal Science, 2015, DOI: 10.2298/TSCI150728203P

20. S. Popa, S. Boran, Rev. Roum. Chim.,2016, 61, 11-12, 851.

21. S. Popa, S. Boran, Rev.Rou. Chim.,2015, 60, 10, 991.

22. G. Mosoarca, P. Negrea, M. Motoc, M. Craciunescu, M. Anghel, D. David, Revista de Chimie, 2009, 60, 6, 636.

23. G. Mosoarca, V. Pode, Revista de Chimie, 2009, 60, 8, 836.

24. G. Mosoarca, P. Negrea, C. Vancea, M. Motoc, M. Anghel, D. David, Revista de Chimie, 2010, 61,10, 983.

25. G. Mosoarca, A. Negrea,Journal of Environmental Protection and Ecology, 2012, 13, 1, 198.

26. I. Lazau, C. Vancea, Romanian Journal of Materials, 2012, 42, 3, 270.

27. C. Vancea, I. Lazau, Central European Journal of Chemistry, 2014, 12, 7, 804.

28. I. Lazau, C. Vancea, G. Mosoarca,Romanian Journal of Materials, 2013, 43, 2, 210.

29. C. Vancea, G. Mosoarca,A. Negrea,A. Latia, R.M. Jurca, Romanian Journal of Materials, 2016, 46, 3, 296. 